\title{
The association between psycho-socio-demographic factors and substance abuse in Iranian male bodybuilders
}

\author{
Hooman Angoorani ${ }^{1,}$, , Behnoosh Tayyebi ${ }^{2}$ \\ ${ }^{1}$ Assistant Professor of Sports Medicine, Department of Sports and Exercise Medicine, Hazrat Rasool-e-Akram Hospital, Iran University of \\ Medical Sciences, Tehran, IR Iran \\ ${ }^{2}$ Faculty Member of Islamic Azad University, Tehran North Branch, Tehran, Iran
}

Email address:

hoomanangoorani@yahoo.com (H. Angoorani), btayyebi@gmail.com (B. Tayyebi)

\section{To cite this article:}

Hooman Angoorani, Behnoosh Tayyebi. The Association between Psycho-Socio-Demographic Factors and Substance Abuse in Iranian Male Bodybuilders. American Journal of Sports Science. Vol. 3, No. 1, 2015, pp. 13-17. doi: 10.11648/j.ajss.20150301.13

\begin{abstract}
Background: This study was conducted to investigate the association between psycho-socio-demographic factors and substance abuse in Iranian male bodybuilders. Material and methods: 906 male bodybuilders from 103 randomly selected gymnasia in Tehran participated in this research. By interviews via questionnaires, the following data over age, employment, average monthly family income, family size, gymnasium area $\left(\mathrm{m}^{2}\right)$, number of trainers, number of gymnasium members, initiation time (months), weekly duration of sporting activity (hours), monthly cost of sporting activity, purpose of participating in sporting activity, mental health as well as body image (via General Health Questionnaire and Multidimensional Body-Self Relations Questionnaire, respectively), and history of substance abuse were collected. Results: All samples were male bodybuilders within the age range of 14 to 56 years (25/7+/-7/1). Substance abuse was reported in 140 (15/5\%) of the subjects. Amphetamine was reported as the most commonly-used illicit drug (13/2\%). Monthly family income, number of family members, enhancement of self-esteem, maintaining fitness, and satisfaction over body parts were associated with substance abuse. Conclusion: Some psycho-socio-demographic factors including family income, family size, enhancement of self-esteem, maintaining fitness, and satisfaction over body parts were associated with substance abuse among male bodybuilders.
\end{abstract}

Keywords: Substance, Drug, Abuse, Bodybuilders, Sport

\section{Introduction}

The sport-drug relationship has always been an important concern for the scientific community and there is a plethora of research into the patterns of drug abuse in athletes [1]. Participating in sports is supposed to be protective against drug abuse [2, 3]. Nevertheless, the prevalence of drug abuse among athletes of different disciplines has encouraged many researchers over the years to investigate the whys and the wherefores of this phenomenon $[4,5]$. There seems to be a general consensus among the researchers that in the sportdrug relationship, the kind of drug and different characteristics of a sporting activity are the key factors $[1,6$, 7]. There is a new trend of substance especially psychoactive drug abuse by athletes [8]. Even with strict regulations of doping [9], illicit drugs are used by athletes to help them enhance their performance $[10,11]$. Several studies have shown that many of sports people use substances and drugs such as human growth hormone, thyroid hormones, insulin, clenbuterol, ephedrine, amphetamine and ... to look more muscular or have a better performance. [12-15] Concern about the serious side effects of substance abuse such as cardiac, neuroendocrine and psychiatric effects has increased over the last decade. $[16,17,18,19,20]$ Therefore, many of researchers have focused on the determination of the predisposing and risk factors for substance abuse in order to develop an effective preventive strategy against it. [10, 11, 18] Presumably, psycho-socio-demographic factors seem to be related to substance abuse, however very few studies $[15,21]$ point toward those factors among bodybuilders. Some psycho-socio-demographic factors such as age, job, education level, income, purpose of participating in sporting activity, mental health, and body image seem to be associated with substance abuse $[14,15,21]$; however, the results are inconsistent in literature on the issue. In this research, the association between some psycho-socio-demographic factors 
with anabolic-androgenic steroid as well as substance abuse among male bodybuilders in Tehran, Iran was investigated.

\section{Material \& Methods}

\subsection{Design and Setting}

This study is one of few surveys regarding substance abuse done in 103 randomly-selected gymnasia in Tehran. The present study was conducted from November 2007 to May 2008 and included 906 randomly-selected male bodybuilders.

\subsection{Samples and Sampling}

One hundred and three gymnasia (clubs) were selected using simple (one level) random sampling. From these clubs, 929 bodybuilders were invited who, at the time was sampling, were present at the club. Inclusion criteria for the study were: 1) Male gender, and 2) Age between 13 and 60. Exclusion criteria were: 1) Subject aborting the study, or 2) Lack of clear response to the questions. From those invited, 906 agreed to participate in the study (response rate $=97.5 \%$ ).

\subsection{Codes of Ethics}

Verbal consent was secured from the athletes and assurance was given that the data would be kept strictly confidential. All participants were given information about the purpose of the study. Participants' names were not recorded. This study has been conducted according to the 'Ethical Principles for Medical Research involving Human Subjects' of the Helsinki Declaration which is approved by the ethics committee of the Research Center for Substance Abuse and Dependence of Iran.

\subsection{Process}

Data on participants' Psycho-social and demographic characteristics, sporting activity patterns, as well as substance abuse history were collected via interviews which took about 45 min for each participant, using structured questionnaires.

\subsection{Independent Variables}

Independent variables included the followings: Age, employment status, average monthly family income, family size, gymnasium area $\left(\mathrm{m}^{2}\right)$, number of trainers, number of gymnasium members, initiation time (months), weekly duration of the sporting activity (hours), monthly cost of the given sporting activity, purpose of participating in the sporting activity, and history of any substance use. The purpose of participating in the sporting activity was defined by the answers to the following six phrases (yes/no): 1) to gain a higher social level, 2) to attract more attention, 3) to enhance one's self-esteem, 4) to enhance one's sports performance, 5) to have a healthy life, and 6) to maintain one's fitness. Moreover the mental health of the athletes as well as their body image was assessed via General Health Questionnaire (GHQ28) and Multidimensional Body-Self Relations Questionnaire-Appearance Scales (MBSRQ-AS), respectively. The GHQ28 as a well-known popular screening tool in psychiatry has four subscales: physical symptoms, anxiety and insomnia, social dysfunction and depression. For grading the tests, each answer from right to left is assigned as zero, one, two and three scores. A total score is obtained from the sum. This questionnaire had been previously validated in Iran by Malakouti et al. [22] Also the MBSRQ-AS as a well-validated self-report inventory for the assessment of body image is a 34-item measure that consists of 5 subscales Appearance Evaluation, Appearance Orientation, Overweight Preoccupation, Self-Classified Weight, and the Body Areas Satisfaction Scale (BASS). This questionnaire had been previously validated in Iran by Rahati. [23]

\subsection{Main Outcome}

The dependent variable was substances use (self-reported data). It was assessed by using the following question:

"Until now, have you ever tried any type of substance such as amphetamine, crystal meth, glass, ecstasy, opium, narcotic drugs, cocaine, heroin, grass, hashish, alcohol or other illicit substances"?

\subsection{Statistical Analysis}

The sample had a confidence interval of $2 \%$, for an estimated prevalence of $68 \%$ for ergogenic agents use according to one previous epidemiological report in Iran [24] and a total of 30,000 , based on the estimate of Iran bodybuilding and Power Lifting Federation. The data was analyzed using the SPSS statistical package application program. To compare non-normally distributed variables, the Mann-Whitney $U$ test was used and the information was given as mean and standard deviation. All independent variables were entered into a multiple logistic regression model to determine the associated factors of substance abuse in body builders using forward selection method. The missing values in the analysis were relatively few. A $p$ value less than 0.05 was considered significant.

\section{Results}

\subsection{Participants}

From a total of 906 participants with mean age of 25.7 (standard deviation $-\mathrm{SD}=7.1$ ) years (minimum of 14 and maximum of 56$), 140(15.5 \%)$ bodybuilders reported a history of substance use. The most commonly abused substance was amphetamine (13.2\%). 3,4-methylenedioxy$\mathrm{N}$-methylamphetamine (MDMA) was the most commonly abused form of amphetamine (13.1\%). 87(9/6\%) and $133(14.6 \%)$ reported a history of hashish use and alcohol consumption, respectively. No one reported the use of opium, narcotic drugs, cocaine or heroin.

$\mathrm{Up}$ to the commencement time of the study, the participants had worked out an average of 20 months at an average of 6 hours per week in gymnasia. Also, sports clubs had, on average, 2 trainers and 160 members. 


\subsection{Associated Factors of Substance Abuse in Bodybuilders}

The results of regression analysis demonstrated that monthly family income $(p=0.028)$, number of family members $(p=0.043)$, and satisfaction of one's body parts (a subgroup of body image) ( $p=0.045)$ were associated with substance abuse (Table 1). Additionally, among different goals for participating in sporting activity, factors of only enhances one's self-esteem $(p=0.008)$ and maintain one's fitness $(p=0.000)$ were associated with substance abuse.

Table 1. Psycho-socio-demographic characteristics in body builders with and without history of substance use.

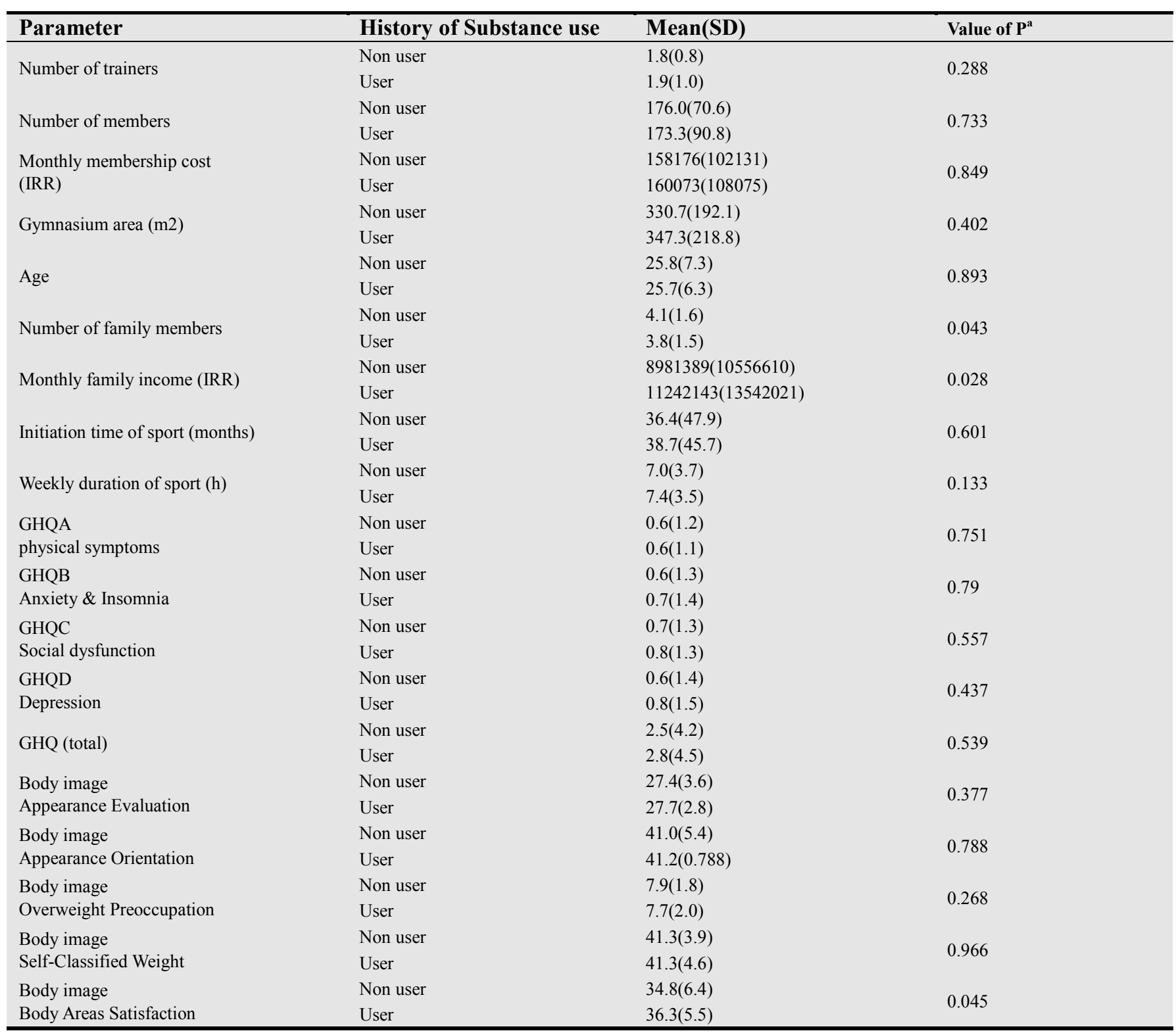

*value of $\mathrm{p}$ less than 0.05 , aMann-Whitney $\mathrm{U}$ test

\section{Discussion}

Undoubtedly, one important concern in the sports community is rapid growth of substance and illicit drug abuse among bodybuilders. In the present study, almost one in seven bodybuilders in Tehran reported substance abuse. This finding is in accordance with several previous studies [15, 25, 26, 27, $28,29]$ which reported that a high percentage of recreational athletes are at risk of use of different substances such as cocaine, opium, heroine, hashish, amphetamine and alcohol. However, as basis of this study, different psycho-socio- demographic parameters, including monthly family income, family size, and satisfaction of one's body parts, enhancement of one's self-esteem and maintaining one's fitness was proven to be associated with substance abuse among bodybuilders which is similar to the results of a number of previous surveys $[12,13,14,15,29]$ Nonetheless, none of the previous surveys specifically covered this subject. Body image problems, especially Muscle Dysmorphia disorder, seem to be associated with substance abuse in athletes. [12, 14, 30, 31, 32, 33] This is relatively in accordance with the findings of this study where satisfaction of one's body parts (a subgroup of body image) 
seemed to be associated with substance abuse. Most likely, using a specific questionnaire to assess muscle dysmorphia in bodybuilders instead of using Multidimensional Body-Self Relations Questionnaire could have lead to finding a stronger relationship between body image and substance.

In the present study, almost $13 \%$ of the body builders admitted to amphetamine use (mostly ecstasy). A previous study in Iran indicated a rise in amphetamine use (especially ecstasy) among the young generation [34], the same as a report by the UN [35] and other regional investigations [36,37]. As athletes, most of the time, use substance, e.g. amphetamine not only for recreation, but also for performance improvement [11, 38], a link between substance use and sports variables would be expected. Within sports-related characteristics in the present study, the only variable with such a link was the motivation for body building. Participation in body building to maintain fitness as well as enhancing self-esteem was linked to higher likelihood of substance use, as opposed to those who sought better sports performance. The literature indicates a higher likelihood of illicit drug use among athletes who participate in sports at competitive Levels [1, 4]. Body builders may use many illicit substances such as amphetamine, hashish, etc. for recreation or for enhancement of sport performance, but the present study did not assess all the possible motivations. Also, level of knowledge about substance was not asked from the participants of this study. This information could shed some light on preventive strategies to explain if drug educational programs could be helpful in this population; but further studies would be needed.

The limitations of this study are as follows: First, the surveys like the present study, by nature, lend to information bias as participants must recall their experiences. Secondly, although cross-sectional studies are a useful and efficient way in obtaining general information about a target population, it is difficult to assess causality. Thirdly, the length and number of questions in this study may have limited survey participation. Lastly, some information may have been lost due to the limitations brought about by validation of the questionnaires thought the authorities in Iran.

\section{Conclusion}

Some psycho-socio-demographic factors seem to be associated with substance abuse among male bodybuilders. The recognition of predisposing factors for substance abuse in bodybuilders can be the cornerstone of providing the educational and preventive programs against drug abuse in gyms.

\section{Role of Funding Sources}

This research was carried out under the financial and scientific supervision of the Research Center for Substance Abuse and Dependency (Darius Institute). However, the Darius Institute had no role in the study design, collection, analysis or interpretation of the data, writing the manuscript, or the decision to submit the paper for publication.

\section{Authors' Contribution}

Authors 1 designed the study, wrote the protocol. Author 2 conducted literature research and provided summaries of previous studies. Author 1 conducted data analysis, interpretation and wrote the first draft of the manuscript. Author 2 performed critical revision and author 1 approved the final manuscript.

\section{References}

[1] Peretti-Watel P, Guagliardo V, Verger P, Pruvost J, Mignon P, Obadia Y. Sporting activity and drug use: Alcohol, cigarette and cannabis use among elite student athletes. Addiction 2003; 98: 1249-56.

[2] McArdle. P, Wiegersma A, Gilvarry E, et al. International variations in youth drug use: the effect of individual behaviors, peer and family influences, and geographical location. Eur Addict Res 2000; 6: 163-9.

[3] Pate RR, Trost SG, Levin S, Dowda M. Sports participation and health-related behaviors among US youth. Arch Pediatr Adolesc Med 2000; 154: 904-11.

[4] Lorene FO, Peretti-Watel P, Grelot L. Cannabis use to enhance sportive and non-sportive performances among French sport students. Addict Behave 2005; 30: 1382-91.

[5] Wagner JC. Abuse of drugs used to enhance athletic performance. Am J Hosp Pharm 1989; 46: 2059-67.

[6] Challier B, Chau N, Predine R, Choquet M, Legras B. Associations of family environment and individual factors with tobacco, alcohol and illicit drug use in adolescents.Eur $\mathbf{J}$ Epidemiol 2000; 16: 33-42.

[7] Margaria R, Aghemo P, Rovelli E. The effect of some drugs on the maximal capacity of athletic performance in man. Eur J Appl Physiol 1964; 20: 281-7.

[8] The world anti doping code: The 2008 prohibited list, international standard. The world anti doping agent. Available at:http://www.wada-ama.org/rtecontent/ document/2008_List_En.pdf. Accessed 2 May 2008.

[9] Clarkson PM, Thompson HS. Drugs and sport. Research findings and limitations. Sports Med 1997; 24: 366-84.

[10] Laties VG, Weiss B. The amphetamine margin in sports. Fed Proc 1981; 40: 2689-92.

[11] Toohey JV. Non-medical drug use among intercollegiate athletes at five American universities. Bulletin on Narcotics UNODC 1978; $3: 7$.

[12] Kanayama G, Pope HG, Jr, Hudson JI. 'Body image' drugs: a growing psychosomatic problem. Psychother Psychosom. 2001; 70:61-65.

[13] Brennan BP, Kanayama G, Hudson JI, Pope HG., Jr Illicit human growth hormone abuse in male weightlifters.Addict Behav. 2011;20:9-13.

[14] Hildebrandt T, Alfano L, Langenbucher JW. Body image disturbance in 1,000 male appearance- and performanceenhancing drug users. J Psychiatr Res. 2010; 44:841-846. 
[15] Angoorani H, Narenjiha H, Tayyebi B, et al. Amphetamine use and its associated factors in bodybuilders: a study from Tehran, Iran. Arch Med Sci.2012;8(2):362-367

[16] Kanayama G, Hudson JI, Pope HG., Jr Long-term psychiatric and medical consequences of anabolic-androgenic steroid abuse: a looming public health concern? Drug Alcohol Depend. 2008; 98:1-12.

[17] Pope HG, Jr, Katz DL. Psychiatric effects of exogenous anabolic-androgenic steroids. In: Wolkowitz OM, Rothschild AJ, editors. Psychoneuroendocrinology. The Scientific Basis of Clinical Practice. Washington: American Psychiatric Press; 2003. pp. 331-358.

[18] Kanayama G, Brower KJ, Wood RI, et al. Anabolicandrogenic steroid dependence: an emerging disorder. Addiction. 2009; 104:1966-1978.

[19] Kanayama G, Brower KJ, Wood RI, et al. Treatment of anabolic-androgenic steroid dependence: emerging evidence and its implications. Drug Alcohol Depend. 2010;109:6-13.

[20] Pope HG, Jr, Kean J, Nash A, Kanayama G, Samuel DB, Bickel WK, Hudson JI. A diagnostic interview module for anabolic-androgenic steroid dependence: preliminary evidence of reliability and validity. Exp Clin Psychopharmacol. 2010;18:203-210

[21] Pope HG, Kanayama G, Hudson JI. Risk Factors for Illicit Anabolic-Androgenic Steroid Use in Male Weightlifters: A Cross-Sectional Cohort Study. Biol Psychiatry. 2012;71(3):254-261.

[22] Malakouti SK, Fatollahi P, Mirabzadeh A, Zandi T. Reliability, validity and factor structure of the GHQ-28 used among elderly Iranians. Int Psychogeriatr. 2007; 19(4):623-34.

[23] Rahati A. Reliability and validity of the Multidimensional Body-Self Relations Questionnaire (MBSRQ) used among female adolescents in Iran. 2004; Master Thesis, Tehran University (not published)

[24] Kashi A, Kargarfard M, Molavi H, Sarlak Z. ergogenic agents abuse among bodybuilders: prevalence and knowledge about the side effects. Olympic Journal. 2006;14:73-86 (Published in farsi)

[25] Perry PJ, Lund BC, Deninger MJ, et al. Anabolic steroid use in weightlifters and bodybuilders: an Internet survey of drug utilization. Clin J Sport Med. 2005;15:326-30
[26] Copeland J, Peters R, Dillon P. Anabolic-androgenic steroid use disorders among a sample of Australian competitive and recreational users. Drug Alcohol Depend. 2000; 60:91-6.

[27] Striegel H, Simon P, Frisch S, et al. Anabolic ergogenic substance users in fitness-sports: a distinct group supported by the health care system. Drug Alcohol Depend. 2006; 81:11-19.

[28] Kanayama G, Hudson JI, Pope HG Jr. Features of men with anabolic-androgenic steroid dependence: a comparison with nondependent AAS users and with AAS nonusers. Drug Alcohol Depend. 2009; 102:130-7.

[29] Matthew D, Jason M, Gomathi S. Predicting future anabolicandrogenic steroid use intentions with current substance use: findings from an internet-based survey. Clin J Sport Med. 2009;19(3):222-227

[30] Santarnecchi E, Dèttore D. Muscle dysmorphia in different degrees of bodybuilding activities: validation of the Italian version of Muscle Dysmorphia Disorder Inventory and Bodybuilder Image Grid. Body Image. 2012;9(3):396-403.

[31] Mosley PE. Bigorexia: bodybuilding and muscle dysmorphia. Eur Eat Disord Rev. 2009; 17(3):191-198.

[32] Babusa B, Túry F. Muscle dysmorphia in Hungarian noncompetitive male bodybuilders. Eat Weight Disord. 2012; $17(1): 49-53$.

[33] Mangweth B, Pope HG Jr, Kemmler G, et al. Body image and psychopathology in male bodybuilders. Psychother Psychosom. 2001;70(1):38-43

[34] Iversen L. Speed, ecstasy, ritalin: the science of amphetamines. Addiction 2007; 102: 1005-7.

[35] Rawson RA, Gonzales R, McCann M, Ling W. Use of methamphetamine by young people: is there reason for concern? Addiction 2007; 102: 1021-2.

[36] Hao W, Xiao S, Liu $T$, et al. The second National Epidemiological Survey on illicit drug use at six highprevalence areas in China: prevalence rates and use patterns. Addiction 2002; 97: 1305-15.

[37] Degenhardt L, Coffey C, Moran P, Carlin JB, Patton GC. The predictors and consequences of adolescent amphetamine use: findings from the Victoria Adolescent Health Cohort Study. Addiction 2007; 102: 1076-84.

[38] Feizzadeh A. Ecstasy: a new substance. Social Welfare 2002; 1: 105-16. 